\title{
O OLHAR POSITIVISTA E A INGENUIDADE HISTORIOGRÁFICA: CRÍTICA DAS FONTES DE PESQUISA EM HISTÓRIA DO DIREITO
}

\section{THE POSITIVIST VIEW AND THE HISTORIOGRAPHIC INGENUITY: CRITICAL OF RESEARCH SOURCES IN HISTORY OF LAW}

Bernardo Pinhón Bechtlufft ${ }^{1}$

\section{RESUMO}

A crença desmedida nas fontes, denunciada por Jacques Le Goff a partir da célebre provocação "todo documento é uma mentira", deve ser sempre rememorada pelo historiador. Este artigo visa dimensionar o quanto a historiografia do direito se vê afetada por um código epistêmico positivista, resultando numa ausência de maior criticidade frente às suas fontes de pesquisa, para, ao final, sugerir caminhos metodológicos alternativos, que possam orientar uma outra técnica de recolha de dados, descomprometida científica, ética e politicamente para com o discurso oficial sobre a história do direito.

Palavras-chave: Historiografia do Direito; Positivismo; Crítica das fontes.

\begin{abstract}
The excessive belief on sources, reported by Jacques Le Goff through known quote "every document is a lie", should always be remembered by historians. This paper aims to measure how much an epstemic positivist code affects the History of Law, which results as an absence of greater criticality towards their research sources. This paper also aims to suggest alternative methodological paths that could guide another technique of data collection, scientifically, ethically and politically unrelated from the official discourse on the History of Law.
\end{abstract}

Keywords: History of Law; Positivism; Source criticism.

\footnotetext{
${ }^{1}$ Mestrando do Programa de Pós-Graduação em Direito no Centro Universitário Internacional (UNINTER), sob orientação do Prof. Dr.António Manuel Hespanha. Bacharel em Direito pelo Centro Universitário Curitiba (UNICURITIBA) e em História pela Universidade Federal de Minas Gerais - UFMG (Brasil). E-mail: bernardo.bechtlufft@gmail.com
} 


\section{INTRODUÇÃO}

Se é bem verdade que do passado sabemos pouco, quase um nada, a velocidade imprimida à contemporaneidade, ao menos no que atine às estruturas políticas e jurídicas que fundamentam a história do tempo presente, estas assustam sobremaneira o historiador. Pois, acompanhando os acontecimentos recentes da história política e jurídica brasileira, qualquer esforço teórico para a compreensão do que venha a ser a vida social há de fatalmente esbarrar na hipocrisia das certezas ou, ao revés, na certeza de todas nossas hipocrisias. A verdade, esse bem por vezes sugerido, mas, a um olhar sincero, posto em absoluto ceticismo, perde sua razão de ser ante a constatação de que o passado, na fórmula rankeana do tal como aconteceu, tende a se matizar e ressaltar outra primeira e fundamental questão, a saber, a de buscar o que nos é dado a conhecer.

Este artigo pretende analisar como o método sob o qual se assenta o trabalho do historiador - em especial na historiografia do direito - através da análise e crítica do como se escolhem e valoram suas fontes. Para tanto, pretendemos primeiro dimensionar o campo de influências exercido pelo positivismo sob o trabalho neste pormenor desempenhado, para, a seguir, analisar a necessidade de recurso a fontes e metodologias outras, conjugando-se a proposta da Escola dos Annales com os trabalhos de Walter Benjamin e Carlo Ginzburg, a fim de que possamos fundamentar a possibilidade de uma outra teoria das fontes na historiografia do direito.

\section{A INFLUENCIA DO POSITIVISMO SOBRE A HISTORIOGRAFIA DO DIREITO}

Muito embora exista uma ampla discussão acerca da impropriedade de se denominar "positivista" uma vasta corrente historiográfica ${ }^{2}$, permeada por múltiplas referências teóricas e metodológicas, é inegável que o pensamento positivista trouxe consigo um peso decisivo sob a constituição das ciências humanas e, foco desta análise, do campo historiográfico. Neste sentido,

\footnotetext{
${ }^{2}$ Sobre a controvérsia, "a historiografia positivista não é o positivismo, embora dele retenha traços essenciais". In: CARDOSO JR., Helio Rebello. Tramas de Clio: convivências entre filosofia e história. Curitiba: Aos quatro ventos, 2001. p. 169.
} 
por "historiografia positivista", pretendemos tão somente denominar uma ampla gama de autores e correntes que se permitem articular por uma matriz epistemológica comum: o positivismo. Assim sendo, desvendar a relação que se estabelece entre o sujeito e o objeto no processo de conhecimento, na generalidade das ciências e, mais especificamente, nas ciências humanas, constitui o primeiro passo à compreensão da influência exercida por este pensamento no campo da produção historiográfica ${ }^{3}$.

Para o positivismo, a realidade é dotada de exterioridade e, como tal, pode ser apreendida objetivamente pelo pesquisador. Sendo assim, pela radical separação entre sujeito e objeto no processo de construção do conhecimento, este tornar-se-ia nada mais que a representação do real, um jogo de reflexos, o espelhamento de uma realidade que, ao investigador, é pré-existente, ofertada de antemão. Desta feita, ao sujeito cognoscente, caberia a tarefa da descoberta, de desvelar a realidade tal como ela é, algo a imprimir-lhe o dever de neutralidade frente aos fatos, afastando-se, pois, de compreensões e juízos de valor trazidos pelo sujeito no processo de construção do conhecimento.

Transposta a questão ao campo das ciências humanas, a elaboração positivista se reflete sob uma compreensão harmônica da realidade social, a qual seria regida por leis naturais $e$ imutáveis. Caberia, portanto, ao cientista social, desvelar o conjunto de leis que regem a naturalidade das relações sociais, o que seria possível pelo recurso a um mesmo método utilizado pelas ciências naturais. Assim sendo, pela homogeneidade epistemológica conferida às ciências humanas e naturais, a produção do conhecimento, nas humanidades, limitar-se-ia ao esforço de compreensão causal dos fenômenos sociais, em explicação refratária a juízos de valores, ideologias e preconceitos advindos do sujeito cognoscente.

A existência de um código epistêmico comum é, portanto, a chave para a compreensão da influência exercida pelo positivismo no seio das ciências humanas. Com efeito, ela permite uma unidade de análise, a partir da qual tornar-se-ia possível o trânsito entre os vários campos do saber, os quais, embora referidos cada qual a um específico objeto, tendem a se articular em torno a uma compreensão total, universal da vida humana. Isso não significa, contudo, que a

\footnotetext{
3 Neste particular, por uma denominação haurida pelo estatuto epistemológico da produção historiográfica, controversamente dita "positivista", seguimos a compreensão trazida por FONSECA, Ricardo Marcelo. Positivismo, Historiografia Positivista e História do Direito. In: Direito. Curitiba: Juruá, 2009. p. 39-66. 
especificidade de cada um dos campos do saber se faça apagar, em suas matizes e particularidades. Pelo contrário. Com isso, pretendemos destacar tão somente um complexo de influências recíprocas de conceitos e compreensões que permitem ao pesquisador, atento ao pressuposto teórico e metodológico desta corrente, dialogar com outros saberes e, assim, formatar um olhar positivista sobre o universo que circunda a análise de um determinado objeto.

Desse modo, entre a filosofia de Augusto Comte (1798-1857), a historiografia de Leopold von Ranke (1795-1880), a sociologia de Émile Durkheim (1858-1917) e, claro está, o pensamento jurídico de Hans Kelsen (1881-1973), vislumbramos bem mais uma unidade de perspectiva, sob a qual se assenta a possibilidade de compreensão harmônica da complexidade de objetos que fundamentam a existência de cada um dos específicos campos do saber. Neste sentido, pretendemos destacar o aspecto relacional do conhecimento, isto é, o como conceitos e compreensões inscritas em outros campos se permitem articular, consciente ou inconscientemente, em uma totalidade de compreensão. Com efeito, e naquilo que especificamente importa aos limites do presente trabalho: nós, juristas, somos demasiado influenciados por uma compreensão positivista, isto é, comteana, durkheimeana e rankeana, do processo sócio-histórico.

Evolutiva, teleológica, progressiva, racional, científica, linear, contínua, harmônica, oficial, construída pelos grandes homens e revelada pelos grandes feitos: a perspectiva lançada pelo positivismo, antes de voltar-se à compreensão do passado, do universo de experiência, visa bem mais a celebração do tempo presente, a glorificação da contemporaneidade. De fato, na advertência de Hespanha, há um duplo efeito ao conhecimento que sob estas premissas se constroem: (a) a naturalização de práticas e institutos que se pretendem legitimar por um discurso trans-histórico, ou seja, como se frutos da tradição; (b) a subtração da dimensão política, ou seja, eminentemente conflitiva na conformação do direito para fixar-se na análise do produto final, acabado, vencedor (HESPANHA, 1997). E, a se embasar por uma sofisticada "técnica de recolha de dados" (BOURDIEU, 2012, p. 25), a partir da qual o esforço de (re)construção teórica do objeto, obediente aos pressupostos teóricos do positivismo, tudo isso há de reduzi-lo a um específico e delimitado patamar: a verdade, vislumbrada em termos tais, se buscará, única e exclusivamente, a partir de fontes oficiais.

Neste sentido, a técnica positivista de reconstrução teórica do objeto, obediente à feição oficial que se pretende conferir à verdade, implica na rigidez do controle do processo de seleção e 
utilização das fontes da produção historiográfica e jurídica. Ora, é sintomático que essa "revolução das fontes"4 se faça sentir a partir do positivismo, isto é, mediante uma ratio cognoscendi que identifica no escrito, oficial, documental, a segurança necessária à produção científica. O primado documental é o correlato historiográfico da compreensão legalista da realidade jurídica. A segurança jurídica vislumbrada pelo positivismo (escrita, oficial, formal) bebe na mesma fonte historiográfica de Ranke, a qual identifica que a história apenas se pode fundamentar em documentos oficiais, por um dever de segurança. Elimina-se, por conseguinte, todo o valor que o discurso histórico identificava desde Heródoto ao relato, à crônica, àquilo que me disseram. Tudo o que não se documenta é mito, fábula: não se presta, pois, à ciência ou à verdade. Conforme Fustel de Coulanges:

Lois, chartes, formules, chroniques et histoires, il faut avoir lu toutes ces catégories de documents sans en avoir omis une seule. [...] Nous rencontrerons [...] plusieurs opinions modernes qui ne s'appuient pas sur les documents; nous devrons être en état d'affirmer qu'elles ne sont conformes à aucun texte, et pour cette raison nous ne nous croirons pas le droit d'y adhérer. [...] Le lecture même des documents ne servirait à rien si on la faisait avec des idées préconçues. [...] Son unique habileté consiste à tirer des documents tout ce qu'ils contiennent et à n'y rien ajouter de ce qu'ils ne contenient pas. Le meilleur des historiens est celui qui se tient le plus près des textes, qui les interprète avec le plus de justesse, qui n'écrit et même ne pense que d'après eux ${ }^{5}$. (COULANGES, 1888, p. 29-30).

Ora, que a concepção positivista seja problemática, é algo visível à historiografia da contemporaneidade. Afinal, a verdade científica não é senão uma ilusão, um efeito que se confere às custas do apagamento de todo um procedimento de recolha e seleção das fontes. Nestes termos, o discurso que exsurge do caminho metodológico proposto, calcado na restrição do objeto em termos tais - isto é, valorando-se única e exclusivamente o documental, a fonte escrita - há de

${ }^{4}$ Conforme Fonseca, a profissionalização do ofício de historiador, seguindo-se a orientação de Leopold von Ranke, tem por primeiro objeto a realização de uma "revolução das fontes", por intermédio da qual restringir-se-ia o universo de análise do historiador unicamente às fontes "oficiais, documentais, pois desse modo pretende-se atingir uma certa segurança no seu uso e manejo". In: FONSECA, op. cit., p. 55.

5 "Leis, cartas, fórmulas, crônicas e histórias, é preciso ter lido todas estas categorias de documentos sem omitir uma sequer. [...] Nós encontraremos [...] várias opiniões modernas que não se apoiam em documentos; nós deveremos estar em condições de afirmar que não estão em conformidade a nenhum texto, e por esta razão não nos cremos com o direito de aderir a elas. [...] A leitura dos documentos não serviria para nada se nós a fizéssemos com ideias preconcebidas. [...] A sua única habilidade (do historiador) consiste em tirar dos documentos tudo o que eles contêm e em não acrescentar nada do que eles não contêm. O melhor historiador é aquele que se mantém o mais próximo possível dos textos." (Tradução minha). In: COULANGES, Fustel de. Histoire des instituitions politiques de l'ancienne France. Paris: Hachette, 1888. p. 29-30. Disponível em: <http://gallica.bnf.fr/ark:/12148/bpt6k61703d/f5.item.zoom>. Acesso em: 14 jul. 2016. 
fatalmente contrariar o propósito científico último, qual seja a aproximação para com a verdade. Dito em termos outros, não há espaço para a verdade quando o método e a técnica utilizados pretendem limitar o nosso universo analítico de compreensão.

Com efeito, é de se reconhecer, avançou muito a História do Direito em reconhecer a necessidade de uma crítica exterior das fontes, a partir da qual a lei, enquanto fonte de pesquisa jurídica e historiográfica, não se possa pensar em uma dimensão axiológica tal como somente o positivismo jurídico kelseneano quis conferir. Falta, contudo, a nosso ver, trilhar o caminho às últimas consequências, isto é, de modo a se fundamentar junto também à historiografia do direito: (a) um discurso crítico sobre o passado do direito, de modo a se escancarar que o objeto histórico, pensado em termos tais, positivistas, cumpre com um objetivo ideológico não-declarado, qual seja, o apagamento da dimensão eminentemente política da conformação do direito; (b) uma crítica interior das fontes, pensada sobretudo a partir do trabalho de Jacques Le Goff e Walter Benjamim, reconhecendo-se, consoante a proposta da Escola dos Annales, que as fontes tradicionais se devem conflitar a outras, não necessariamente jurídicas.

\section{APORTES CRÍTICOS À HISTORIOGRAFIA DO DIREITO: FUNDAMENTOS ÉTICO-POLÍTICOS PARA UMA CRÍTICA INTERNA DAS FONTES DE PESQUISA}

No processo de produção do conhecimento científico, o pesquisador não se coloca em posição de tão somente espelhar seu objeto, isto é, registrá-lo de forma asséptica, neutra e desinteressada. Pelo contrário, o universo dos fatos é criado por ele, de modo problemático ${ }^{6}$, em tarefa sobre a qual o sujeito necessariamente se interpõe, através da seleção meticulosa das fontes (o que) e métodos (o como) que serão utilizados. Não existem, portanto, "fatos puros", haja vista que "a atividade do cientista consiste numa operação de seleção dos fatos que não são pertinentes, interessantes, quantificáveis e julgados contingentes" (MORIN, 2014, p. 43).

Disto resultam três questões à presente discussão sobre a historiografia do direito. São elas: (a) como se selecionam as fontes de pesquisa da história do direito?; (b) qual a relação que o

\footnotetext{
${ }^{6}$ De acordo com Lucièn Febvre, o ofício do historiador não se traduz pela compilação de fatos, mas sim pela sua reconstrução, tendo em vistas problemas e hipóteses afirmadas pelo sujeito durante o processo de conhecimento. Sendo assim, para ele, "pôr um problema é precisamente o começo e o fim de toda história. Sem problema, não há história, mas narrações, compilações. A história 'cientificamente conduzida' realiza as duas operações que se encontram na base de todo o trabalho científico: formular problemas e construir hipóteses". FEBVRE, Lucién. Combates pela história. Lisboa: Presença, 1989. p. 22.
} 
historiador do direito estabelece com as suas fontes?; (c) quais as consequências que advém da predileção, pela historiografia do direito, por um determinado método de seleção e trabalho para com as suas fontes?

Pois bem.

Como dito alhures, a transposição do código epistêmico positivista às ciências humanas, a partir da elaboração de métodos e técnicas semelhantes às adotadas pelas demais ciências, visa conferir à análise do social a possibilidade de um conhecimento seguro e rigoroso, tal como o experimentado pelas ciências naturais. Disto, resulta a predileção da historiografia positivista pelo registro documental, ou seja, escrito e oficial, declinando-se formas outras - notadamente a crônica - sob as quais o conhecimento histórico poderia se assentar.

Tal questão, por sua vez refletida sobre a historiografia do direito, se faz sentir com enorme peso sobre o conhecimento que aqui se produz. Afinal, dada a especificidade do seu objeto, o jurídico, há uma íntima relação deste com o primado do documental, bem como do oficial. Nessa perspectiva, a história do direito seria aquela que exsurge dos documentos, dos registros oficiais do Estado, das fontes escritas, nada havendo fora disso. Haveria aqui, portanto, uma relação de extrema confiança depositada pelo historiador nas fontes utilizadas, que se reflete na identificação do passado de práticas, conceitos e instituições jurídicas a partir, única e exclusivamente, do documento, uma prova viva do vivido. A técnica de recolha de dados, portanto, pretende refletir o resultado material da atividade investigativa: o documento é o registro fiel do passado jurídico, o qual não se deve interpretar, mas sim, e tão somente, ser descrito pelo pesquisador. E eis aqui, porém, a origem dos muitos problemas que advém da ausência de uma maior criticidade do historiador do direito para com as fontes de seu trabalho.

Primeiro, porque tal perspectiva negligencia algo que nos é essencial: tal como é possível e provável que jamais saibamos, no futuro, o que veio a ocorrer do passado, igualmente, nos é dado a conhecer apenas parcela ínfima de sua concreta manifestação. Com isso, pretendemos dizer que não existem provas do passado, mas sim fragmentos, indícios, colocados ao historiador como em um lampejo, um instante de perigo ${ }^{7}$ (BENJAMIN, 1987, p. 224). A

\footnotetext{
7 Acerca do conceito "instante de perigo", Löwy denomina o momento em que o passado se afigura em sua realidade ao historiador, abalando sua crença sobre a relação entre presente/passado. In: LÖWY, Michael. Walter Benjamin: aviso de incêndio. Uma leitura das teses "Sobre o conceito de história". Rio de Janeiro: Boitempo, 2005. p. 65.
} 
atividade do historiador, nesta perspectiva, não se traduz pelo reflexo do passado, mas sim de reconstrução e preenchimento de lacunas, pela empatia/acedia do presente para com o passado. Dito de outro modo, o ontem é uma rememoração do hoje, o reavivamento do outrora, segundo os quadros mentais hodiernos.

Mas não apenas. Segundo: o historiador não deve reconhecer estes fragmentos do passado como meros lampejos, como a experiência rememorada. Ele deve, a todo instante, duvidar do peso destes fragmentos, da vontade de verdade que se pretende afirmar a partir deles. Neste sentido, imprescindível o recurso ao trabalho de Le Goff (1990), para o qual, a partir da distinção teórica entre monumentos ${ }^{8}$ e documentos $^{9}$,

O documento não é qualquer coisa que fica por conta do passado, é um produto da sociedade que o fabricou segundo as relações de forças que aí detinham o poder. Só a análise do documento enquanto monumento permite à memória coletiva recuperá-lo e ao historiador usá-lo cientificamente, isto é, com pleno conhecimento de causa. (LE GOFF, 1990, p. 545).

O trabalho do historiador, nesta análise, não pode prescindir de uma atitude crítica interna, isto é, orientada para a análise (e dúvida) sobre as condições históricas de produção e reprodução de suas fontes. Não basta, portanto, questionar o que diz o documento (teoria do reflexo). É necessário um algo mais: discutir quais as motivações, individuais e coletivas, conscientes e inconscientes, que se impõem na elaboração de um documento e, sobretudo, quantas são as perspectivas possíveis e negligenciadas a partir da vontade de verdade que se pretende afirmar na produção de seu conteúdo. Em última análise,

O documento é monumento. Resulta do esforço das sociedades históricas para impor ao futuro - voluntária ou involuntariamente - determinada imagem de si próprias. No limite, não existe um documento-verdade. Todo o documento é mentira. Cabe ao historiador

${ }^{8}$ De acordo com Le Goff, monumento é "tudo aquilo que pode evocar o passado, perpetuar a recordação, por exemplo, os atos escritos". Desta feita, cumpre ele com uma função eminentemente política, posto que se vincula ao "poder de perpetuação, voluntária ou involuntária, das sociedades históricas (é um legado à memória coletiva) e o reenviar a testemunhos que só numa parcela mínima são testemunhos escritos". In: LE GOFF, Jaques. Documento/Monumento. In:

História e Memória. Campinas: Editora Unicamp, 1990. p. 535-536.

9 Por sua vez, o termo documento adquire o significado de "prova", de "testemunho histórico". Tal caracterização se faz sentir especialmente a partir da constituição do campo historiográfico, sobretudo a partir da influência de uma epistemologia positivista no seio das ciências humanas. De acordo com Le Goff: "O documento que, para a escola histórica positivista do fim do século XIX e do início do século XX, será o fundamento do fato histórico, ainda que resulte da escolha, de uma decisão do historiador, parece apresentar-se por si mesmo como prova histórica. A sua objetividade parece opor-se à intencionalidade do monumento. Além do mais, afirma-se essencialmente como um testemunho escrito". In: LE GOFF, op. cit., p. 536. 
não fazer o papel de ingênuo. Os medievalistas, que tanto trabalharam para construir uma crítica - sempre útil, decerto - do falso, devem superar esta problemática porque qualquer documento é, ao mesmo tempo, verdadeiro - incluindo, e talvez sobretudo, os falsos - e falso, porque um monumento é em primeiro lugar uma roupagem, uma aparência enganadora, uma montagem. É preciso começar por desmontar, demolir esta montagem, desestruturar esta construção e analisar as condições de produção dos documentos-monumentos. (LE GOFF, 1990, p. 548).

Voltamos, pois, ao problema da seleção das fontes à historiografia do direito. Afinal, se o documento não é prova, mas sim um mero fragmento, o qual esconde uma vontade de verdade, ressaltando o que quer ressaltar e desdenhando do que deseja desdenhar, como lidar com a seleção das fontes em torno àquelas que revelem, exclusivamente, um caráter jurídico? Em outros termos: se a atividade de seleção das fontes é o que cria o objeto, como enfrentar a constatação de que as fontes por excelência do trabalho do historiador do direito são, por um lado, fragmentárias, e por outro, portadoras de uma vontade de verdade que omite o real sentido do acontecido?

Confessamos: uma resposta segura à armadilha metodológica exposta parece-nos sobremaneira impossível. Temos, contudo, indícios de um caminho, com o qual uma historiografia do direito talvez possa se satisfazer. Vejamos:

Em primeiro lugar, em compromisso para com a verdade e ciência, é necessário que o trabalho de escolha das fontes na historiografia do direito se faça sem prescindir de uma crítica interna destas mesmas fontes, isto é, sobre as suas condições de produção e vontades de verdade ocultas sob seu conteúdo. Se não o fizermos, cremos, corremos um grave risco: a glorificação dos fragmentos do passado como provas, d'onde brota a possibilidade de afirmar o direito como tradição que espraia no presente, como se fruto do progresso, de uma evolução, advinda da sempre asséptica ou bem-intencionada ação de seus produtores. Os fragmentos são, eles próprios, duvidosos, e, como tal, devem ser a todo instante confrontados com demais indícios legados do passado, de modo que nenhuma fonte e perspectiva analítica possa escapar a uma análise da história do direito. "É proibido proibir", diríamos, recorrendo a Bourdieu (2012): precisamos duvidar de toda a extensão do que um documento traz e, sobretudo, recuperar a dimensão daquilo que ele não quis dizer ${ }^{10}$.

Subverter a mitologia jurídica sob a qual se assenta um discurso histórico sobre o direito a partir de fontes não-criticadas internamente é, portanto, essencial. Fazê-lo, a nosso ver, não

10 Neste sentido, ponderando-se a questão metodológica posta por Bourdieu, "a liberdade extrema que eu prego, e que me parece ser de bom senso, tem como contrapartida uma extrema vigilância das condições de utilização das técnicas, da sua adequação ao problema posto e às condições do seu emprego". In: BOURDIEU, 2012, p. 26 
revela apenas o compromisso ético do pesquisador para com o conhecimento, orientado para a verdade, mas fundamentalmente político, para com a transformação da realidade social. É, neste sentido, combater os pilares da perspectiva dos vencedores, escovando a história a contrapelo ${ }^{11}$ (BENJAMIN, 1987, p. 225), em dois de seus alicerces fundamentais: (a) negando-lhe legitimação pela crítica de seu caráter monumental, mitológico; (b) afirmando-se, do passado, tradições e vontades de verdade ocultas, inscritas para além da vontade de verdade que se imprime em documentos oficiais, afirmados pela história oficial.

Ao fazê-lo, fomentando um discurso crítico sobre a história do direito, satisfazemos também uma lacuna essencial à própria produção do conhecimento jurídico, tão mitologicamente assentado em irrefletidas representações de tradições, evoluções e uma autoimagem do progresso de práticas, conceitos e instituições. O recurso a um contra-discurso historiográfico, por sua vez, permite constituir um discurso sobre o passado afeito à visão dos vencidos, a se espraiar na criticidade do próprio direito hodierno ${ }^{12}$, manco de um dos pilares maiores de sua legitimação de seu compromisso para com o poder e a opressão: o discurso histórico.

\section{A ESCOLA DOS ANNALLES: CAMINHOS METODOLÓGICOS À SUPERAÇÃO DO DOGMATISMO POSITIVISTA NA ESCOLHA DAS FONTES DA HISTORIOGRAFIA DO DIREITO}

Deve-se à inovadora proposta metodológica da Escola dos Annales o peso de uma "revolução documental", a qual houve por ampliar o acervo de fontes de pesquisa do trabalho historiográfico. Neste sentido, dada a expectativa de produção de um conhecimento total, que abarcasse todas as possíveis esferas do passado humano, bem como a admissão que as fontes de pesquisa historiográficas são lacunares, tendo em vista o caráter fragmentário dos indícios legados ao tempo presente, houve a abertura da historiografia para um universo de possibilidades

\footnotetext{
11 Por "escovar a história a contrapelo", Löwy identifica dois sentidos ao termo: (a) histórico, ou seja, ir contra a versão oficial da história, opondo-lhe a tradição dos oprimidos; (b) político, ou atual, no qual a redenção/revolução apenas pode advir pela recusa ao curso natural das coisas, o sentido da história identificado a partir do discurso oficial. In: LÖWY, op. cit., p. 74.

12 A este respeito, "A teoria crítica provoca a autoconsciência dos agentes e dos grupos que estão em desvantagem e/ou desigualdade e sofrem as injustiças por parte dos setores dominantes, das classes ou elites privilegiadas. Nesse sentido, ideologicamente a teoria crítica tem uma formalização positiva na medida em que se torna processo adequado ao esclarecimento e à emancipação, indo ao encontro dos anseios, interesses e necessidades dos realmente oprimidos". In: WOLKMER, Antônio Carlos. Introdução ao pensamento jurídico crítico. 9. ed. São Paulo: Saraiva, 2015. p. 35-36.
} 
antes circunscrita mormente ao registro escrito, estatal e oficial. Ora, se "tudo é história"13, necessariamente tudo também se tornará fonte do trabalho historiográfico, auxiliando-se o historiador no preenchimento, por seus quadros mentais hodiernos, de cada uma das lacunas do tempo. A história, neste sentido, deixa de ser o amontoado de fatos, datas, lugares e nomes de homens célebres. Ela é o conhecimento que busca satisfazer problemas colocados pelo tempo presente e, como tal, "devolve ao historiador a liberdade na exploração do material empírico" (REIS, 2004, p. 78).

Cumpre à historiografia do direito, portanto, não negligenciar fontes outras de pesquisa, para que se elimine a possibilidade de construção de um discurso cujas ideias estejam fora do lugar (SCHWARZ, 1992). Afinal, não há como pensar tradições, conceitos, instituições jurídicas sem os sujeitos, sem a cultura, sem o político: devemos restituir o direito a seu devido lugar. A música, a literatura, o folclore, as práticas sociais, a crônica, o registro documental não jurídico, tais como agendas, diários, jornais: todas as fontes são necessárias ao historiador do direito para dimensionar a conformação do sistema jurídico a partir de turbações ambientais, isto é, do esforço de mediação e tensão epistêmica havida para com os demais sistemas sociais, políticos, culturais, cotidianos, dentre outros (TEUBNER, 1989).

Pensamos ser insuficiente, porém, o recurso a novas fontes. Para a produção do conhecimento historiográfico é fundamental o recurso a um instrumental metodológico outro, capaz de confrontar a suas fontes a partir de uma crítica interna de suas condições de produção, para que possamos acessar o passado em maior fidedignidade. Neste sentido, há duas trilhas metodológicas, em especial, que nos auxiliam para com este tratamento diverso, que pretendemos conferir às fontes da historiografia do direito. São elas: (a) o paradigma indiciário de Carlo Ginzburg; (b) o recurso a uma abordagem de caráter micro-historiográfico.

a. $O$ paradigma indiciário. No festejado capítulo "Sinais: Raízes de um paradigma indiciário", o historiador italiano Carlo Ginzburg (2007) bem ressalta que o conhecimento historiográfico deve se afastar de toda uma pretensão afeita às ciências galileicas. Isso, porque o objeto de trabalho do historiador, as relações humanas no tempo, elas não se podem pautar pela

${ }^{13}$ O lema, geralmente atribuído ao pensamento de Karl Marx, se vê ressignificado pela proposta historiográfica dos Annales. Se, por um lado, ao filósofo alemão, a exortação dá conta de que nada pode escapar ao movimento regular da história, pensada a partir do materialismo histórico, o recurso ao excerto pelo movimento historiográfico francês ressalta que tudo pode ser objeto de análise pelo historiador, em contraponto, aqui, à restrição do escopo analítico do historicismo/positivismo. (Nota do autor). 
possibilidade de repetição de seus fenômenos e pelo esforço de quantificação, submetendo a análise de seus dados ao primado da matemática. Ora, quantos homens lutaram na Batalha das Termópilas? Com efeito, jamais saberemos, temos apenas indícios, legados ao tempo presente, sobretudo a partir do relato de Heródoto. A história, neste sentido, é a ciência do concreto, do universo particular, afastando-se, pois, de qualquer esforço de generalização de suas conclusões. Ela é qualitativa e, por excelência, indemonstrável.

Aproxima-se, pois, o trabalho do historiador, das artes médicas, cuja conclusão pela doença, em suas causas profundas, apenas se pode verificar a partir de uma detida análise de suas indiciárias manifestações, sintomáticas, consequenciais. Do mesmo modo, acerca-se da técnica psicanalítica, cujo primado de análise se permite verificar sobretudo dos lapsos, manifestações marginais de um inconsciente. Ainda, avizinha-se da perícia, realizada pelo detetive e pelo expert em obras de arte, para os quais o ato de desvendar a cena do crime ou a falsificação pautar-se-ia pela observância primeira não de suas causas, mas sim dos seus efeitos, de seus menores sinais, resquícios da manifestação fenomênica de uma vontade.

Por isso, o autor inova ao trazer a possibilidade de construção do conhecimento historiográfico a partir de um paradigma indiciário, isto é, da análise semiótica dos pequenos sinais de um universo microcósmico. Trata-se, portanto, da elaboração de um método de interpretação das fontes

[...] centrado sobre os resíduos, sobre os dados marginais, considerados reveladores. Desse modo, pormenores normalmente considerados sem importância, ou até triviais, 'baixos', forneciam a chave para aceder aos produtos mais elevados do espírito humano (GINZBURG, 2007, p. 149-50).

A historiografia do direito, dominada por fontes que tangenciam, sobremaneira, a história oficial e uma premente vontade de verdade de seus produtores, tem muito a se beneficiar do recurso à proposta de Carlo Ginzburg. Ora, tal como a cena do crime se permite verificar, por Sherlock Holmes, pelas menores cinzas de cigarro ao chão, o estudo do passado jurídico requer a abdicação de uma visão positivista em face de suas fontes tradicionais, isto é, reconhecendo-se a existência de estratégias de conformação do olhar do interlocutor em face de seu conteúdo. Sendo assim, devemos não mais destinar a análise à centralidade que o documento queira conferir à posteridade. Pelo contrário: das menores manifestações indiciárias, dos lapsos inconscientes de seus produtores, é que podemos vislumbrar o que o direito é, apesar de negar-se a dizê-lo. 
Transposta a questão às fontes da historiografia do direito, assim cremos o quanto o discurso sobre o passado de instituições e práticas jurídicas ainda está para ser escrito. Basta pensar, neste sentido, na tensão entre poder e verdade, que, a exemplo das revelações da delação de Sérgio Machado na Operação Lava-jato, historicamente se permitem afirmar em meio ao jurídico. Ousemos, portanto: é preciso buscar, por seus lapsos lacanianos, pelos descuidos de seus operadores, os limites da conformação do objeto jurídico e as tensões sociais, políticas, culturais e econômicas que lhes são subjacentes. Com isto, haveremos de acessar o passado do direito para além do ornamento ético e bem-intencionado que corresponde à vontade de verdade que os homens de outrora quiseram legar, a seu tempo e à posteridade, e que agora nos atinge sob a fórmula do progresso, da evolução, da história dos vencedores. Coloquemos, pois, as ideias jurídicas, demasiado humanas, também em seu devido lugar.

b. A abordagem micro-historiográfica. Aparentemente o recurso a uma análise de cunho micro-historiográfico, fragmentário, parece distante do universo da historiografia do direito. Uma perspectiva pluralista, porém, do universo jurídico, com foco na tensão epistêmica havida entre o sistema jurídico e os demais sistemas normativos, torna imprescindível o recurso a fontes e métodos outros, capazes de confrontar o que hoje tomamos por excelência como jurídico com a complexidade da vida social. Eis aqui, portanto, a nosso ver, a necessária contribuição que a microhistória pode trazer à compreensão do passado do direito.

Em breves linhas, por microhistória, tratamos de uma inflexão no paradigma historiográfico da Escola dos Annales, a partir dos autores de sua terceira geração (Le Goff, Duby, Nora, dentre outros). Com isto, a fragmentariedade do objeto social é levada às últimas consequências, abdicando-se de toda e qualquer pretensão para com uma análise total, globalizante, tal como a praticada por suas gerações anteriores (Bloch, Febvre, Braudel). O objeto do trabalho do historiador, neste sentido, tornar-se-ia cada vez mais reduzido, com clara predileção do pesquisador à análise do universo periférico, marginal. Em síntese:

A terceira geração talvez possa ser dita pós-estruturalista, também de forma impura. Sob a influência da antropologia, prefere descrições, narrativas, indivíduos, biografias, excluídos, periféricos, marginais, sexo, bruxaria, mundos históricos micro... Não se busca mais um sentido global para a história e considera-se impossível a integração da consciência (REIS, 2005, p. 80). 
A microhistória quer, portanto, resgatar uma dimensão humana, mais profunda, da experiência histórica. Com isto, afasta-se da pretensão generalizante, que queira identificar, por exemplo, a mentalidade do ateniense comum com o pensamento de Platão ou Aristóteles. Ora, se poucos foram os legados do passado à contemporaneidade, necessariamente devemos reputar a valiosa contribuição das fontes micro-históricas, que permitem uma compreensão da vida social em maior amplitude, a partir da justaposição e confronto de um maior conjunto de fontes, poucas, mas felizmente legadas à contemporaneidade.

Assim sendo, tratamos os sinais, os indícios presentes nas fontes, não como exemplos de ações abrangentes e disseminadas, mas sim como uma prática singular, a qual se permite estabelecer e elaborar em torno às condições de possibilidade abertas à sua produção e reprodução. Não se trata, pois, de compreender o medievo, em perspectiva totalizante, mas a vida social de uma pequena aldeia, por suas menores práticas cotidianas, por sorte documentadas e expostas à contemporaneidade, as quais se permitem articular a uma visão mais ampla, sobre um menor espaço social.

A nosso ver, abre-se aqui uma possibilidade de análise em muito negligenciada pela historiografia do direito, tão arraigada à irrefletida análise macrohistórica, mas que pode contribuir bastante para uma melhor compreensão de seu objeto. E duas são as questões, neste particular, que parecem exsurgir com grande força desta possibilidade metodológica.

Primeiro, se por uma contingência histórica um maior volume de fontes micro-historiográficas possa ter sido legado à contemporaneidade, há uma maior possibilidade de articulação do objeto jurídico ao complexo normativo social, político, cultural, possibilitando, pois, a análise do universo epistêmico que se articula - e por vezes rivaliza - com o direito. É dizer: a microhistória permite a análise das turbações ambientais que conformam o jurídico, em sua dinâmica cotidiana, possibilitando, pois, ressaltar uma dinâmica comunicativa, conflitiva ou não, da formação histórica do direito.

Segundo, a existência de um maior contingente de fontes afeitas a uma perspectiva micro-historiográfica permite aclarar exatamente algo que as fontes eminentemente jurídicas isto é, oficiais, estatais, escritas - pretendem, por sua vez, desdenhar e ocultar. Trata-se, pois, da história dos vencidos, em que o contraponto micro-historiográfico, aproximado de uma dinâmica 
mais concreta da vida social, autoriza resgatar, situando o discurso oficial para além da vontade de verdade que conforma a produção e reprodução das fontes eminentemente jurídicas.

Com isto, aliando-se a análise do jurídico pelo paradigma indiciário e um método micro-historiográfico, cremos ser possível a afirmação de uma história do direito a partir de uma perspectiva marginal, isto é, dos direitos que foram historicamente negligenciados, negados, subtraídos, apagados, utilizados em proveito político e social de poucos opressores, exploradores, das classes e grupos dominantes.

\section{CONSIDERAÇÕES FINAIS}

Na elaboração de um trabalho de cunho historiográfico, a escolha das fontes e a constituição de um método capaz de refletir criticamente os dados obtidos não poderá prescindir jamais de uma indagação, anterior, sobre as condições de produção e reprodução das próprias fontes que o passado legou à contemporaneidade. Afinal, sem uma crítica interna das fontes, bem como um método capaz de relevar dimensões ocultas pela história dos vencedores, perspectiva fundamentalmente atrelada às fontes tradicionais da historiografia do direito, estaríamos de todo presos a uma perspectiva legitimante, apologética de um passado que tanto buscou ocultar de si, e que clama, do presente, uma ação redentora: a história do direito sob a perspectiva dos vencidos.

Não basta à historiografia do direito, portanto, uma crítica sobre a natureza das fontes utilizadas, isto é, indicando-se as razões pelas quais o campo historiográfico deva abdicar de uma perspectiva mormente legalista do passado de nossas instituições, institutos e práticas jurídicas. É preciso algo mais: o estabelecimento de bases para a formação de um discurso capaz de resgatar uma dimensão eminentemente conflitiva - e, claro está, histórica - sobre a qual se funda a normatização da vida social.

Ao fazê-lo, seguindo-se a modesta contribuição trazida pelo presente artigo, satisfaz-se uma dupla pretensão do autor, simultaneamente científica, em se buscar do conhecimento uma maior profundidade, reconhecendo do seu objeto uma complexidade que se situa para muito além de suas fontes tradicionais, e ético-política, ao se fundamentar um discurso sobremaneira 
incidente sobre a crítica da fundamentação e legitimação histórica de práticas jurídicas contemporâneas.

\section{REFERÊNCIAS}

BENJAMIN, Walter. Obras escolhidas: Magia e Técnica, Arte e Política. v. 01. 3. ed. São Paulo: Brasiliense, 1987.

BOURDIEU, Pierre. O Poder Simbólico. 16. ed. Rio de Janeiro: Bertrand Brasil, 2012.

CARDOSO JR., Helio Rebello. Tramas de Clio: convivências entre filosofia e história. Curitiba: Aos quatro ventos, 2001.

COULANGES, Fustel de. Histoire des instituitions politiques de l'ancienne France. Paris, Hachette, $1988 . \quad$ p. $29-30 . \quad$ Disponível <http://gallica.bnf.fr/ark:/12148/bpt6k61703d/f5.item.zoom>. Acesso em: 14 jul. 2016.

FEBVRE, Lucién. Combates pela história. Lisboa: Presença, 1989.

FONSECA, Ricardo Marcelo. Introdução Teórica à História do Direito. Curitiba: Juruá, 2009.

GINZBURG, Carlo. Mitos, emblemas e sinais: Morfologia e História. 2. ed. São Paulo: Cia. das Letras, 2007.

HESPANHA, António Manuel. Panorama Histórico da Cultura Jurídica Europeia. Lisboa: Europa América, 1997.

LE GOFF, Jacques. História e Memória. Campinas: Editora Unicamp, 1990.

LÖWY, Michael. Walter Benjamin: aviso de incêndio. Uma leitura das teses "Sobre o conceito de história". Rio de Janeiro: Boitempo, 2005.

MORIN, Edgar. Ciência com Consciência. 16. ed. Rio de Janeiro: Bertrand Brasil, 2014.

REIS, José Carlos. Escola dos Annales: A inovação em História. 2. ed. São Paulo: Paz e Terra, 2004.

História e Teoria: Historicismo, Modernidade, Temporalidade e Verdade. 2. ed. Rio de Janeiro: FGV, 2005. 
TEUBNER, Gunther. How the Law Thinks: Toward a Constructivist Epistemology of Law. Law \& Society Review, v. 23, n. 05, 1989, pp. 727-758.

WOLKMER, Antônio Carlos. Introdução ao pensamento jurídico crítico. 9. ed. São Paulo: Saraiva, 2015. 